\section{Endoscopic Zenker diverticulotomy using the window technique: a technical trick to improve the field of view}
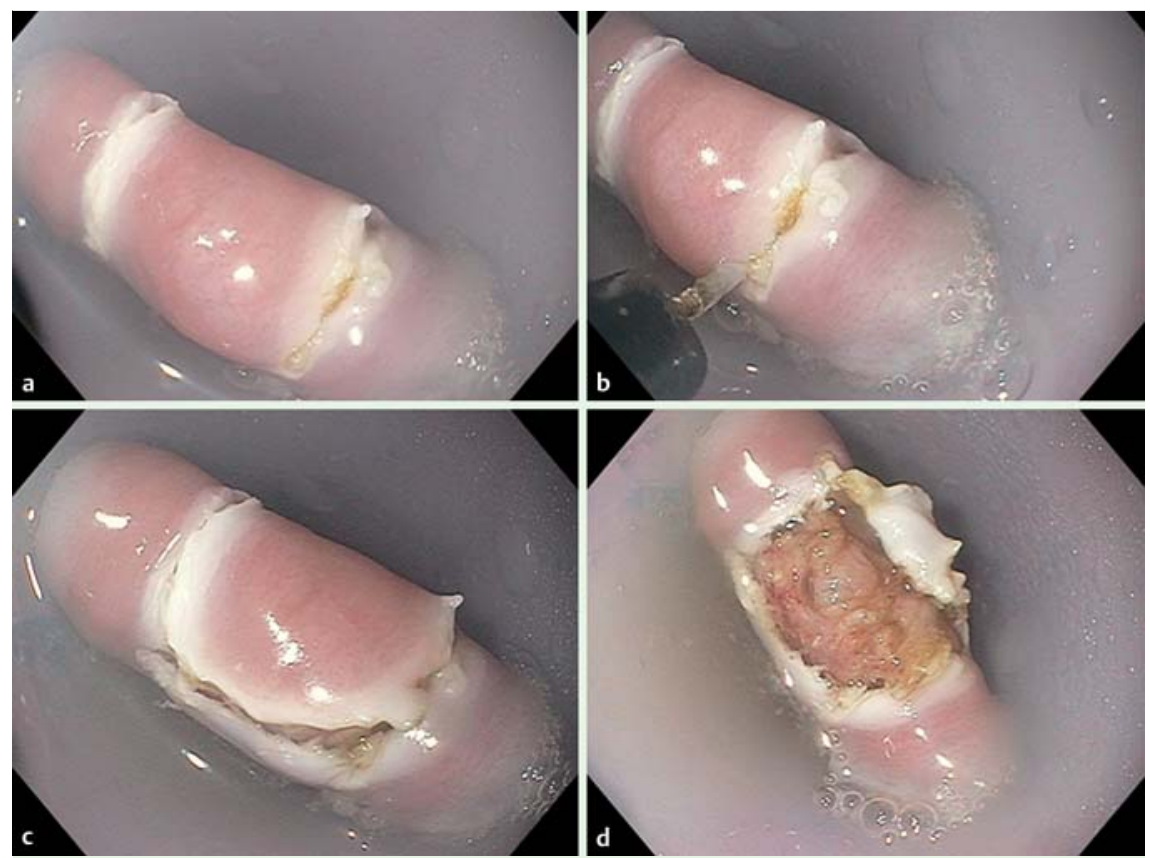

Fig. 1 Endoscopic views of the initial step in endoscopic Zenker diverticulotomy with mucosal cutting to create the window showing: $\mathbf{a}$ the lateral sides cut; $\mathbf{b}$ the inferior incision being made; $\mathbf{c}$ the appearance after three sides have been cut; $\mathbf{d}$ the final appearance after removal of the mucosal flap.

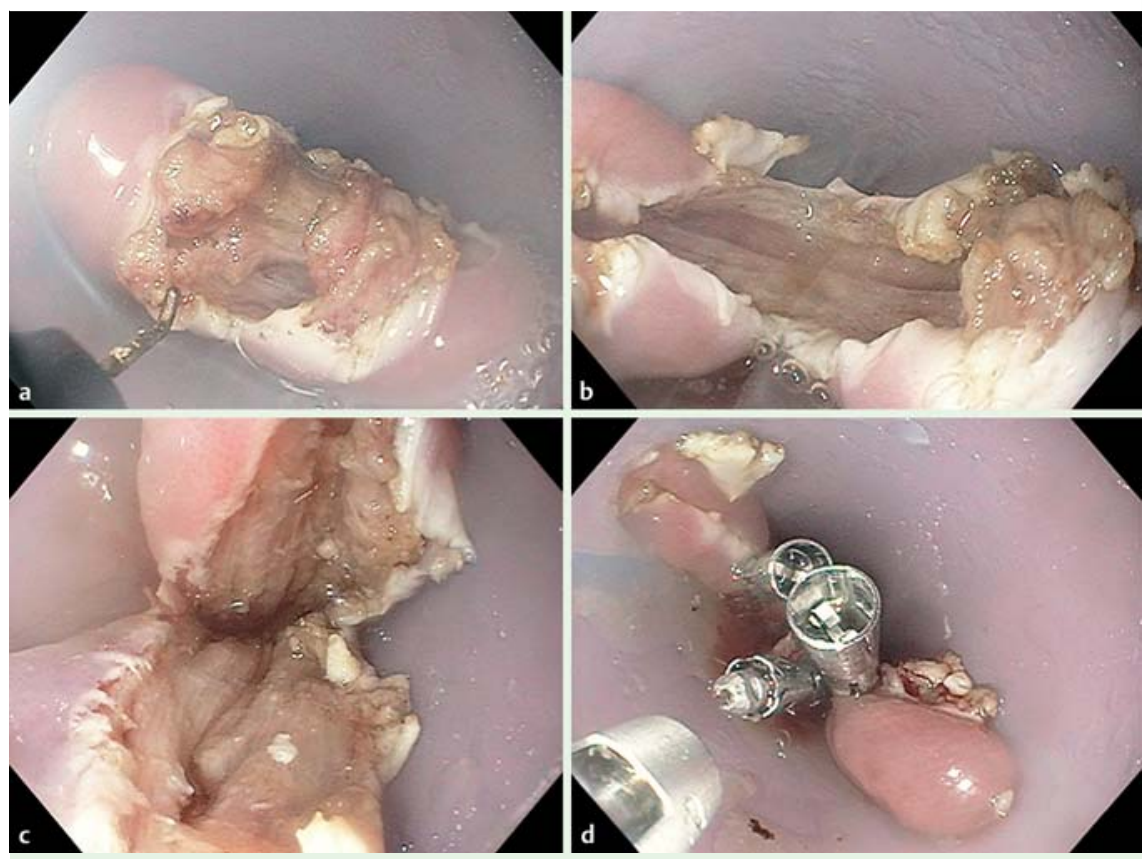

Fig. 2 Appearance of the myotomy site with the mucosal window showing: a the exposure of the muscular fibers at the initial stage of the myotomy; $\mathbf{b}$ a deeper view; $\mathbf{c}$ the view after total myotomy has been performed; $\mathbf{d}$ the view following closure with hemoclips.

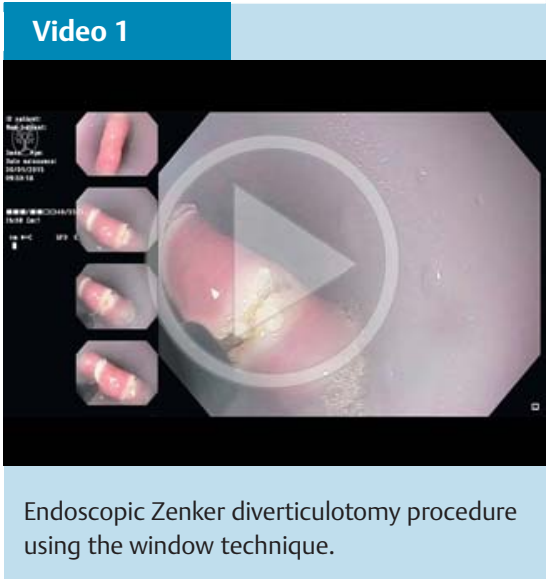

Endoscopic diverticulotomy is a safe, effective, and simple technique to treat patients with symptomatic Zenker's diverticulum [1]. The endoscopic management was demonstrated to be as effective as surgical external diverticulotomy in most cases and can be recommended as the first choice [2]. Diverticuloscope-assisted diverticulotomy has been demonstrated to be safer and more effective than the capassisted procedure [3]. The main benefit of the diverticuloscope is to improve exposure of the muscular fibers by stretching them [4].

In our practice, we additionally use a technical trick called the "window technique" to improve the field of view before the myotomy. After insertion of the diverticuloscope, we initially cut a small square of mucosa to enlarge the space and expose the muscular fibers ( $\bullet$ Fig. 1). This step usually takes 1 minute. A square, measuring approximately $5 \mathrm{~mm}$, is cut on the four sides and then removed. We usually use a Hook-knife (Olympus, Tokyo, Japan) to create this window with Endocut electric current (ERBE VIO 300D, Tübingen, Germany).

Thanks to this mucosal window, the cricopharyngeal fibers are stretched and visible ( Fig.2). Without the mucosal window, the two sides of the sectioned mucosa can obscure the myotomy site and prevent perfect control of the depth of cutting. In contrast, the mucosal window helps to 
enlarge the field of view and allows us to precisely catch the muscular layer by hooking.

This technique is commonly used in our unit and we present the case of a 57-yearold woman with a 5-cm diverticulum ( Fig. 1 and $\bullet$ Fig. 2; $\bullet$ Video 1). She was successfully treated using this trick without any adverse events and was discharged after 2 nights.

To summarize, endoscopic diverticulotomy is effective and safe but the window technique is a simple trick to improve the field of view and facilitate the myotomy.

Endoscopy_UCTN_Code_TTT_1AO_2AN

Competing interests: None

\section{Jérôme Rivory ${ }^{1}$, Ala Almahayawi ${ }^{1}$, Sabine Roman², Laura Calavas ${ }^{1}$, Jean-Christophe Saurin', Thierry Ponchon $^{1,3}$, Mathieu Pioche ${ }^{1,3}$}

${ }^{1}$ Gastroenterology and Endoscopy unit, Edouard Herriot Hospital, Lyon, France ${ }^{2}$ Digestive Physiology, Edouard Herriot Hospital, Lyon, France

3 INSERM U1032, Labtau, Lyon, France

\section{References}

1 Huberty V, El Bacha S, Blero D et al. Endoscopic treatment for Zenker's diverticulum: long-term results (with video). Gastrointest Endosc 2013; 77: 701 - 707

2 Shahawy S, Janisiewicz AM, Annino D et al. A comparative study of outcomes for endoscopic diverticulotomy versus external diverticulectomy. Otolaryngol Head Neck Surg 2014; 151: 646-651

3 Costamagna $G$, Iacopini $F$, Tringali $A$ et al. Flexible endoscopic Zenker's diverticulotomy: cap-assisted technique vs. diverticuloscope-assisted technique. Endoscopy 2007; 39: $146-152$
4 Costamagna G, Iacopini F, Bizzotto A et al. Prognostic variables for the clinical success of flexible endoscopic septotomy of Zenker's diverticulum. Gastrointest Endosc. Epub ahead of print 2015 Sep 3. DOI: 10.1016/j. gie.2015.08.044

\section{Bibliography}

DOI http://dx.doi.org/

10.1055/s-0042-101388

Endoscopy 2016; 48: E63-E64

(c) Georg Thieme Verlag KG

Stuttgart · New York

ISSN 0013-726X

\section{Corresponding author}

\section{Mathieu Pioche, MD}

Endoscopy Unit - Digestive Disease Department H Pavillon - Edouard Herriot Hospital 69437 Lyon

France

Fax: +33-4-72110147

mathieu.pioche@chu-lyon.fr 